\title{
TIPOLOGIA CIVIL: SUBSISTÊNCIA DOS CORTADORES DE CANA-DE-AÇUCAR EM BARRA DO BUGRES- MT
}

Adelino A. S.Marinho ${ }^{1}$

Veruska Pobikrowska Tardivo ${ }^{2}$

Renata Barros Abelha Kabeya ${ }^{3}$

RESUMO: Com a vinda da corte portuguesa para o Brasil, no inicio do século XIX, a densidade demografia no Rio de Janeiro, aumentou substancialmente, mas a cidade não estava preparada para receber esse grande contingente. Muitos sem condições financeiras e culturais ficaram as margens da sociedade. A vida na cidade grande, estava cara, surge neste contexto os cortiços, a nova tipologia civil. Hoje se fala em realidade virtual, em alta tecnologia, apesar de toda essa evolução tecnológica ainda há pessoas que vivem em condições sub-humanas como as do começo do século $X X$, esse mau não é particular dos grandes centros, Barra do Bugres no interior do Mato Grosso também sofre, entendê-lo que esta forma de moradia deve ser readequada, passível de mudanças, uma vez que é insalubre para os moradores que ali usufruem deste degradante espaço.

Palavras-chave: tipologia civil, cortiço, Barra do Bugres.

\footnotetext{
1 Acadêmico do $3^{\circ}$ ano de Arquitetura e Urbanismo da Universidade Estadual de Maringá- DAU UEM (marinho.adelino@gmail.com)

2 Professora Mestre do curso de Arquitetura e Urbanismo da Universidade Estadual do Mato Grosso- UNEMAT (veruska.tardivo@yahoo.com.br)

${ }^{3}$ Professora Mestre em Sociologia. Curso de Matemática. Universidade Estadual do Mato Grosso- UNEMAT. Campus de Barra do Bugres (reabelha@terra.com.br)
} 


\section{Introdução}

A pesquisa tem como objetivo estudar o começo dos cortiços no Brasil e traçar um paralelo entre a obra literária "O Cortiço" de Aluisio Azevedo com as casas dos cortadores de cana-de-açúcar no município de Barra do Bugres, Mato Grosso, levando em consideração as técnicas construtivas no início do século XX, com as atuais. Além disso, procura estabelecer uma paralelo entre o perfil dos moradores do século passado com os de hoje, sempre partindo do pressuposto "O Cortiço" e Barra do Bugres.

O procedimento metodológico utilizado foi: primeiramente uma revisão bibliográfica de caráter histórico, visando realizar um breve panorama sobre o contexto social da colonização brasileira até a importância da cidade do Rio de Janeiro como Capital Nacional. A partir daí foram estudados as técnicas construtivas desse período, para poder então, entender a nova tipologia civil: os cortiços.

\section{Breve Panorama da Colonização do Brasil}

Quando o Brasil foi descoberto pelos Portugueses, não havia interesse por parte dos europeus em colonizar a nova terra. O período pré-colonial compreende os trinta primeiros anos após o "descobrimento", ou seja, de 1500 a 1530 . A preocupação de Portugal por Brasil limitou-se a apenas duas expedições exploratórias.

Aproximadamente em 1530 o governo português enviou para o Brasil a primeira expedição colonizadora, chefiada por Martim Afonso de Souza. Eram cinco navios, cerca de 400 homens, animais, plantas e peças para montar um engenho. Ele percorreu praticamente todo o litoral, enfrentou navios franceses, montou um forte no litoral onde hoje é o Rio de Janeiro, organizou expedições na região sudeste, fundou duas vilas, São Vicente e Santo André, e um engenho, o do Governador.

Mas todo esse esforço não foi suficiente, a coroa portuguesa não tinha recursos para investir no Brasil, uma forma de solucionar esse problema era "privatizar" as terras da colônia. Portugal resolveu dividir a administração das terras brasileiras entre nobres portugueses. Assim o território foi dividido em 15 lotes que deram origem as capitanias. 
Esse sistema não se adequou bem por aqui. O desenvolvimento das capitanias foi desigual, destacando apenas São Vicente, cujo proprietário era Martim Afonso, e Pernambuco cujo proprietário era Duarte Coelho.

Aos poucos foi dada a ocupação do interior do Brasil, em busca de especiarias e drogas, produtos como resinas aromáticas, condimentos e ervas medicinais alcançavam bons preços no mercado externo e eram obtidos pelos jesuítas com o auxílio dos índios. Os jesuítas construíram missões ao longo dos territórios do Paraguai, Rio Grande do Sul, Paraná, Mato Grosso, Mato Grosso do Sul, Amazonas, Pará e Maranhão. Essas missões foram de grande importância para a criação de núcleos populacionais, onde os índios aprendiam a cultura dos "brancos" e principalmente a fé cristã. Além disso, os índios foram alvo da ação dos predadores, que abriram caminho pelos sertões até chegarem às missões.

Por volta do século XVII, na região de Minas gerais, são descobertas as primeiras jazidas de ouro e minérios preciosos no Brasil, começa então o Ciclo do Ouro. A migração para as terra de garimpo, com o objetivo de obter riqueza fácil, fez com que a população da colônia pulasse, de 300 mil, em 1700, para cerca de 3 milhões, no final do século. Sobretudo, no começo do século XIX, a corte Portuguesa transferiu-se para o Brasil, mais especificamente na cidade do Rio de Janeiro, fugindo das tropas de Napoleão Bonaparte.

\section{A cidade do Rio de Janeiro no início do século XIX}

Nos anos anteriores ao século XIX, a cidade do Rio de Janeiro se desenvolveu de forma orgânica ${ }^{4}$, a economia brasileira girava em torno da agricultura, da pecuária e também da mineração por esse fator as cidades coloniais não eram tão populosas. Sob o ponto de vista intelectual, havia na sociedade uma homogeneidade de pensamentos. $\mathrm{Na}$ arquitetura não foi diferente:

[...] No que diz a respeito às construções, duas ou três técnicas praticadas, sempre com os mesmos critérios, sempre com os mesmos partidos, as mesmas feições, havia uma grande unidade arquitetônica, especialmente aquela referente às construções populares, tanto urbanas como rurais[...] (LEMOS, 1976, p. 103)

\footnotetext{
${ }^{4}$ Seguindo a topografia do terreno. (LEMOS, 1979)
} 
Com a vinda da corte portuguesa para o Brasil, em 1808, houve uma reconfiguração decisiva na sociedade e conseqüentemente na arquitetura. Essa transformação coincidiu com um novo pensamento da sociedade européia, era o pensamento tecnicista, decorrente das constantes mudanças provocadas pela Revolução Industrial.

Assim, resultou em alguns meses numa série de provisões destinadas a mudar a qualidade de vida da sociedade carioca. Como por exemplo, a abertura de portos, novas escolas, teatros, imprensa e inúmeras obras públicas. No entanto, a maior parte dessas construções foram financiadas pela elite fluminense, que empolgadas com a chegada da Corte no Brasil investiram na reforma de praças e até na pavimentação de ruas. Mas a motivação principal foi a possibilidade de morarem ao lado do príncipe regente:

Antes, os ricos da cidade não podiam ostentar riqueza. Por isso, as casas eram grandes, mas não tinham luxo. Com a chegada da família real, as regras foram alteradas, diz o historiador e arquiteto Nireu Cavalcanti, professor da UFF (Universidade Federal Fluminense).

A corte Portuguesa exportou da França o estilo arquitetônico em voga naquele país, o neoclássico francês (fig. 01), e trouxe para aqui profissionais franceses que mudaram a cara da cidade carioca, visando à higiene pública e a estética urbana. Foi nesse período que a cidade do Rio de Janeiro passou a dar importância às artes, e funda a Escola Real de Ciências, Artes e Ofício, implantando uma nova linguagem arquitetônica. (BRUAND, 1981)

Ainda segundo Bruand, 1981, a arquitetura era dada a partir da teoria da composição e se configurava pelo: o retorno às formas da Antiguidade Clássica; desaparecem os beirais de telha à vista, que agora são encobertos por platibandas; o frontão triangular é uma das características mais marcantes, tanto na arquitetura religiosa como na civil e a verga do arco pleno substitui a do abatido. 

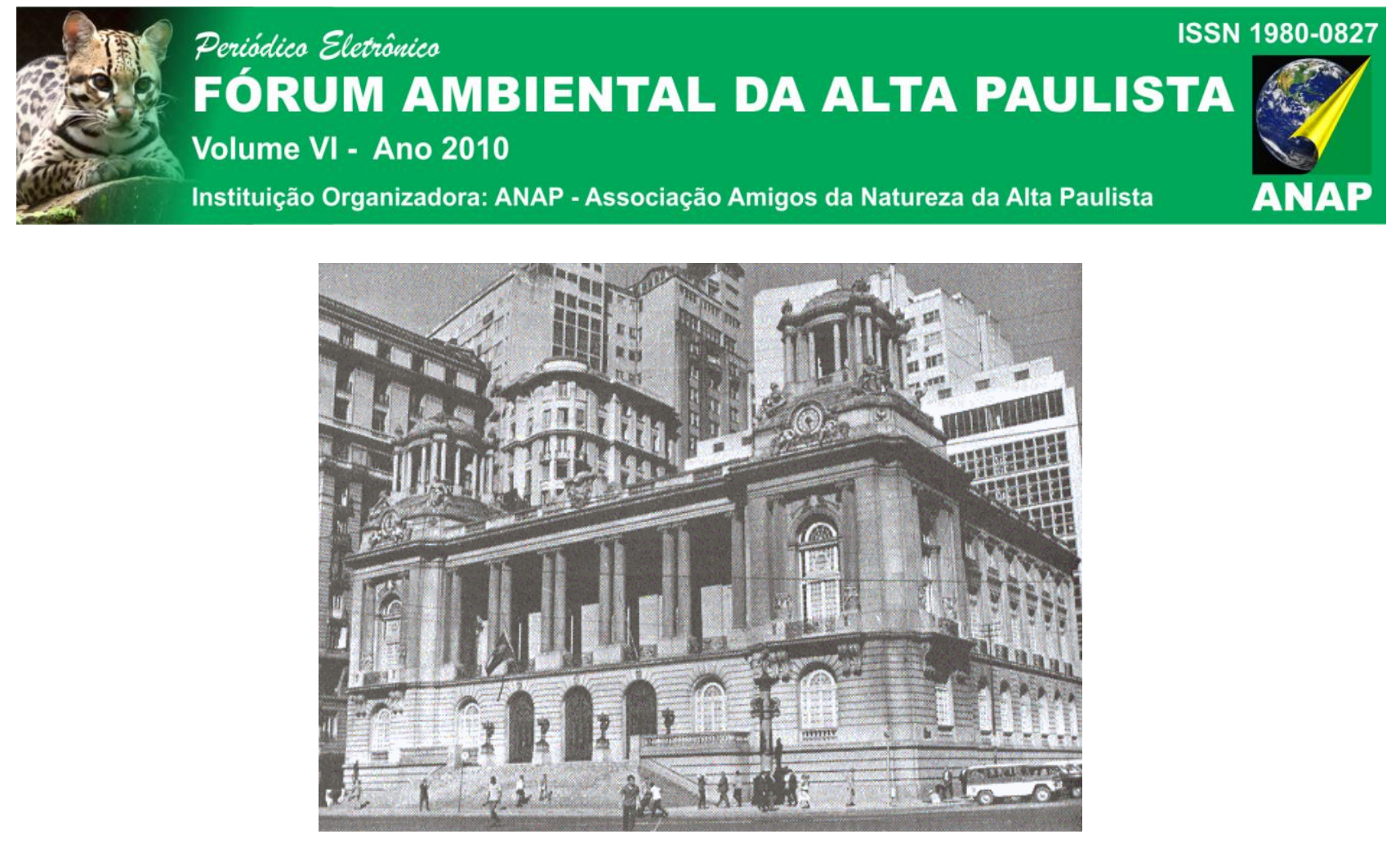

Figura 01: Prefeitura do Rio de Janeiro (fonte: BRUAND, 1981)

Dessa forma o Rio de Janeiro passou a ser a capital do poder, tanto no sentido econômico como cultural, era o núcleo de onde partiam as novas correntes de comportamento envolvendo até a moda, música, mobiliária e as novas maneiras de construir. Isso foi um fator determinante para que muitas pessoas saíssem da zona rural e procurassem emprego nas novas fábricas da cidade grande, o êxodo rural. Grande parte da população teve que se submeter a viver em condições desumanas devido à falta de infra-estrutura dos grandes centros para comportar todos os novos moradores. Surge neste contexto uma nova tipologia de morada, os cortiços.

\section{A comparação entre "O Cortiço" de Aluísio Azevedo e os cortiços do século XIX}

A sociedade estava mudada, novos valores foram inseridos, a realidade agora era os grandes centros, a máquina, o tempo. Surge nesse período uma nova tipologia de morada, os cortiços. Eram conjuntos de pequenas "casas", quartos/salas, sem recuos entre as paredes externas, com banheiros e lavanderias coletivas, construídas de forma desordenadas. Essa temática foi muito bem elucidada na obra literária de Aluísio Azevedo: "(...) e o fato é que aquelas três casinhas, tão engenhosamente construídas, foram o ponto de partida do grande cortiço de São Romão (...)” (ALUíSIO, 1890, p. 4) 
Esse tipo de construção, geralmente é feita sem nenhum planejamento prévio e vai aumentando, de forma aleatória, conforme a disposição econômica do proprietário:

(...) João Romão observava durante o dia quais as obras em que ficava material para o dia seguinte, e à noite lá estava ele rente, mais a Bertoleza, a removerem tábuas, tijolos, telhas, sacos de cal, para o meio da rua, com tamanha habilidade que se não ouvia vislumbre de rumor. Depois, um tomava uma carga e partia para casa, enquanto o outro ficava de alcatéia ao lado do resto, pronto a dar sinal, em caso de perigo; e, quando o que tinha ido voltava, seguia então o companheiro (...)(ALUíSIO, 1890, p. 4)

Quem mora nesse tipo de habitação, geralmente é a classe social menos favorecida, semi-analfabeta que vive a margem da sociedade. O autor faz essa referência quando ele caracteriza os personagens a animais, movidos pelo instinto sexual:

(...) as mulheres precisavam já prender as saias entre as coxas para não as molhar; via-se-lhes a tostada nudez dos braços e do pescoço, que elas despiam, suspendendo o cabelo todo para o alto do casco; os homens, esses não se preocupavam em não molhar o pêlo, ao contrário metiam a cabeça bem debaixo da água e esfregavam com força as ventas e as barbas, fossando e fungando contra as palmas da mão (...). (ALUísIO, 1890, p.18)

E ainda, chega a compará-los a vermes “(...) As corridas até à venda reproduziamse,transformando-se num verminar constante de formigueiro assanhado (...)" (ALUÍSIO, 1890, p.19)

Aluísio busca explorar bem essa temática: o sexo, de quase todas as formas, desde o adultério, prostituição ao lesbianismo, bastante polêmico pra época.

(...)Naquela mulata estava o grande mistério, a síntese das impressões que ele recebeu chegando aqui: ela era a luz ardente do meio-dia; ela era o calor vermelho das sestas da fazenda; era o aroma quente dos trevos e das baunilhas, que $o$ atordoara nas matas brasileiras; era a palmeira virginal e esquiva que se não torce a nenhuma outra planta; era o veneno e era o açúcar gostoso; era o sapoti mais doce que o mel e era a castanha do caju, que abre feridas com o seu azeite de fogo; ela era a cobra verde e traiçoeira, a lagarta viscosa, a muriçoca doida, que esvoaçava havia muito tempo em torno do corpo dele, assanhando-Ihe os desejos,acordando-lhe as fibras embambecidas pela saudade da terra, picando-lhe as artérias, para lhe cuspir dentro do sangue uma centelha daquele amor setentrional, uma nota daquela música feita de gemidos de prazer, uma larva daquela nuvem de cantáridas que zumbiam em torno da Rita Baiana e espalhavam-se pelo ar numa fosforescência afrodisíaca (...) (ALUÍSIO, 1890, p.48) 
Os personagens vão aparecendo ao longo da narrativa, mas o personagem principal é o próprio cortiço. Quando descrito, ele parece ganhar vida. "(...) Eram cinco horas da manhã e o cortiço acordava, abrindo, não os olhos, mas a sua infinidade de portas e janelas alinhadas (...)" (ALUíSIO, 1890, p.17)

Outro fator interessante de ser analisado é a questão de salubridade, que é mínima. O cortiço descrito por Aluísio, não têm uma infra-estrutura básica para a higiene, os banheiros são comunitários, as casas não têm ventilação, o espaço da lavanderia é úmido e praticamente não há espaço entre as casas, conforme os dois exemplos a seguir:

E naquela terra encharcada e fumegante, naquela umidade quente e lodosa, começou a minhocar, a esfervilhar, a crescer, um mundo, uma coisa viva, uma geração, que parecia brotar espontânea, ali mesmo, daquele lameiro, e multiplicarse como larvas no esterco(...)(ALUÍSIO, 1890, p.11)

Ainda comentando sobre a salubridade do cortiço:

A roupa lavada, que ficara de véspera nos coradouros, umedecia o ar e punha-lhe um farto acre de sabão ordinário. As pedras do chão, esbranquiçadas no lugar da lavagem e em alguns pontos azuladas pelo anil, mostravam uma palidez grisalha e triste, feita de acumulações de espumas secas (...)(ALUÍSIO, 1890, p.18) 


\section{Análise das casas dos cortadores de cana-de-açúcar de Barra do Bugres-MT}

Foi analisado as casas dos trabalhadores rurais que vêem do nordeste para cortarem cana na região por um determinado tempo do ano. Geralmente são homens, semi-analfabetos, com faixa etária entre 18 a 35 anos.

Como referência, analisamos os quartos de aluguel de Sra. Evilza, que assim como João Romão em "O cortiço", construiu seus quartos de forma desordenada, sem um planejamento prévio e conforme tinha disposição financeira.

Um dos moradores, destes quartos de aluguel da Sra. Evilza, nordestino, não terminou o ensino médio por falta de oportunidade, paga em média $R \$ 30,00$ por pessoa, dividindo assim seis pessoas por quarto, mais uma vez, pudemos analisar a zoomorfização do homem como citada na obra de Aluísio Azevedo. Quando inquirido sobre privacidade, uma vez que as relações sexuais ocorrem, sobretudo com o aviso antecipado dos colegas de dormitório.

Pudemos averiguar, em visita in loco, no total são seis quartos de madeira, que comportam vinte e quatro homens, ainda existem mais três quartos de alvenaria em estágio de construção. Cada quarto tem em média $20 \mathrm{~m}^{2}$ que comporta: dois beliches, uma geladeira, um televisor e um fogareiro.

Quanto às questões de conforto térmico foram completamente desprezadas, os quartos em sua totalidade são escuros, tem apenas uma janela basculante de $87 \times 90 \mathrm{~cm}$ a 1,20 de peitoril, com vidro canelado, mesmo durante o dia é necessário acender uma lâmpada e quanto à ventilação, o espaço é abafado, úmido e sujo. Sobretudo, a cobertura de toda a construção é feita em fibrocimento, o que deixa ainda mais quentes e desconfortáveis estes quartos (fig. 02, 03 e 04). 


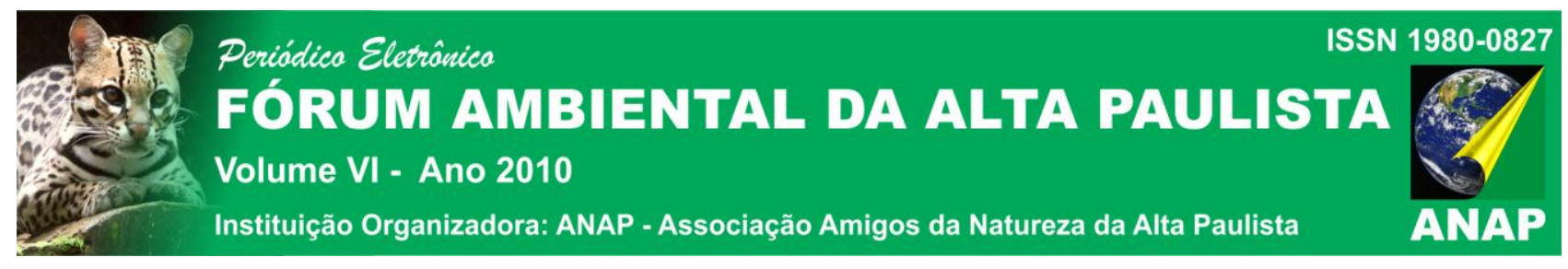

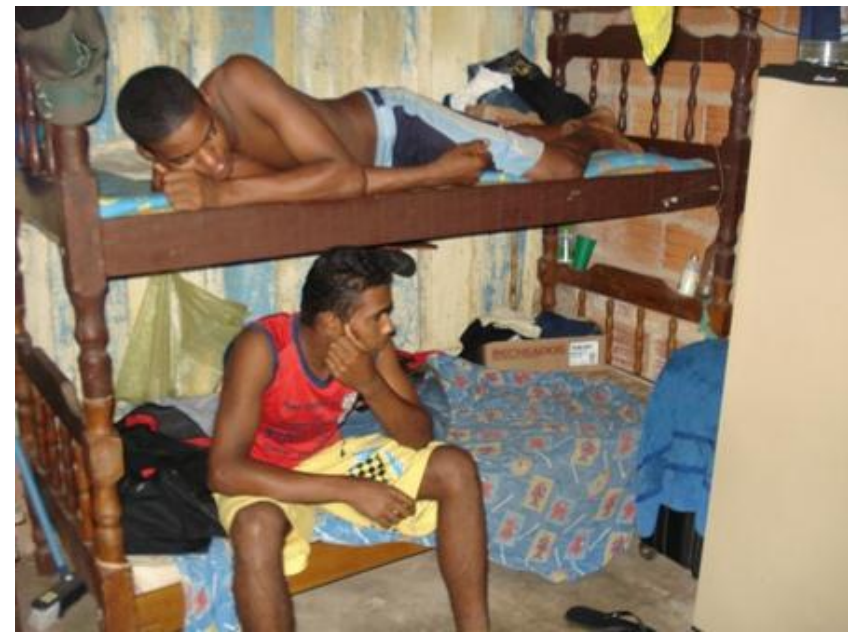

Fig. 02: Vista do interior do quarto (fonte: Adelino A. S.Marinho)

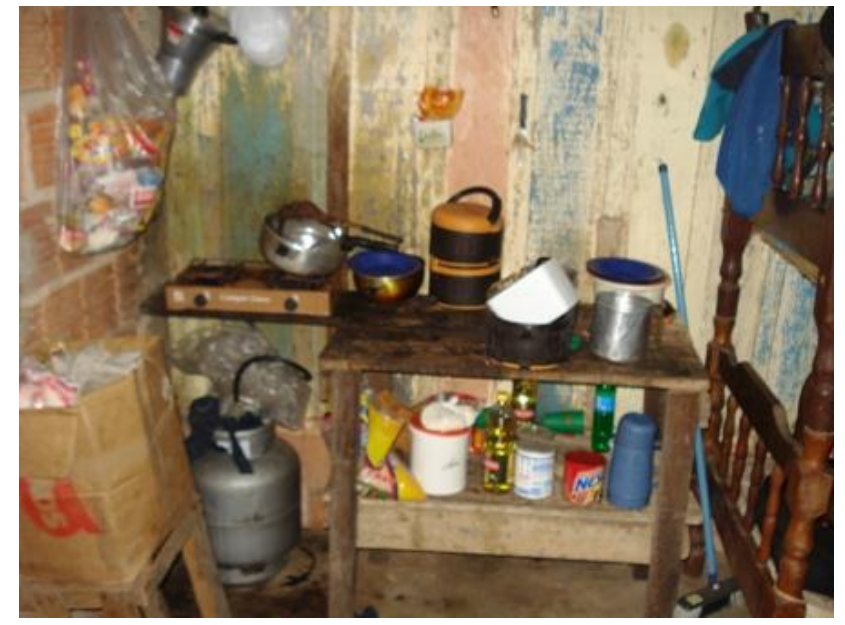

Fig. 03: Vista do interior do quarto, detalhe do fogareiro (fonte: Adelino A. S.Marinho)

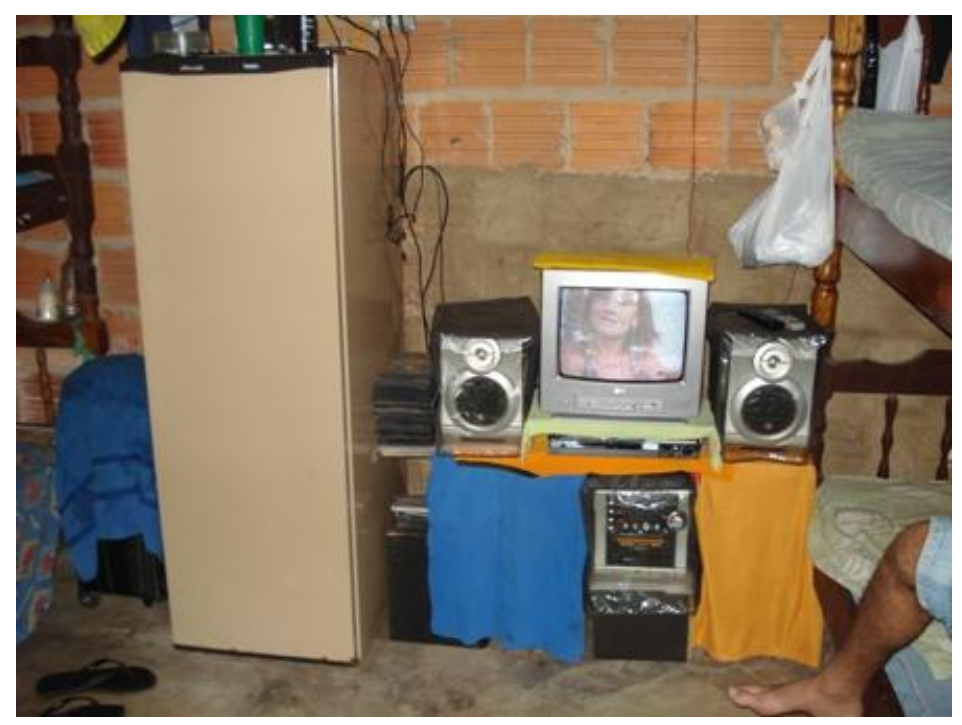

Fig. 04: Vista do interior do quarto, detalhe da geladeira (fonte: Adelino A. S.Marinho)

Os banheiros são de uso comum e são três no total de $1,00 \mathrm{~m} \times 1,50 \mathrm{~m}$, a porta de madeira quase encostada nos sanitários, não há revestimento cerâmico, as paredes internas dos banheiros são de 2,10 m, os sanitários são encardidos (fig. 05 e 06). 


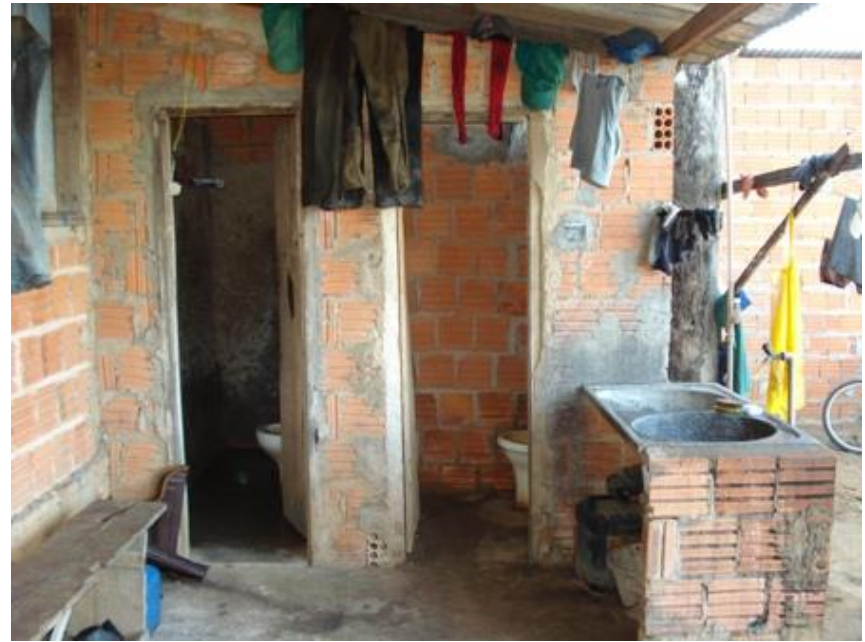

Fig. 05: Vista dos banheiros (fonte: Adelino A. S.Marinho)

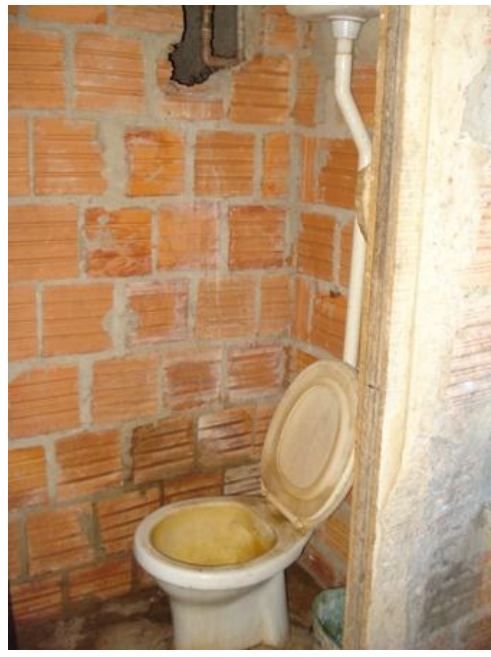

Fig. 06: Vista interna do banheiro (fonte: Adelino A. S.Marinho)

\section{Considerações Finais}

Hoje é comum falar em realidade virtual e alta tecnologia. Surge neste século, uma corrente arquitetura dentro do contexto Pós-moderno chamada de High Tech, pode parecer estranho falar em técnicas construtivas tão geniais e avançadas, quando uma grande parte da sociedade ainda não conhece os benefícios da água tratada ou da rede de esgoto, mas esse paradoxo é uma resultante da fragilidade da nova ordem mundial, que nos assolam desde antes do período colonial. Em Barra do Bugres não é diferente, percebemos que muitas pessoas ainda vivem a margem da sociedade sem nenhuma estrutura básica de moradia.

É preciso que os nossos governantes junto com a sociedade intervenham nessas moradas e dê condições melhores de qualidade de vida. Essa benfeitoria não ficará restrita apenas ao âmbito estrutural, mas também influenciará de forma significativamente na saúde dessas pessoas.

E nós cidadãos, temos por dever pensar num país mais democrático, que insiram essas pessoas no contexto da sociedade e dê condições básicas de moradia, como prevê a constituição brasileira com o direito social à mesma. Ainda pensando, no âmbito profissional, em propostas e em soluções técnica-construtivas simples como os tijolos de adobe, ventilação cruzada, iluminação natural e a volta de técnicas construtivas da 


\section{Perídica Electônica

arquitetura vernacular dessa região podem ser uma das saídas para um novo pensar de uma sociedade mais igualitária

\section{Referências}

BRUAND, Yves. Arquitetura contemporânea no Brasil. São Paulo Perspectiva, 1981.

FERREIRA MARTINS, José Roberto, História, FTD, Rio de Janeiro, 2000.

GARCEZ MARTINS, Paulo César, Através da Rótula sociedade e arquitetura urbana no Brasil no século XVII à XX, São Paulo, humanitas FFLCH/USP, 2001.

LEMOS, Carlos. Arquitetura Brasileira, São Paulo, Editora Melhoramentos, 1979.

SEGAWA, Hugo. O prelúdio da Metrópole, Arquitetura e urbanismo em São Paulo na passagem do século XIX ao XX, São Paulo, ateliê editorial, 2000.

.Chegada da Família Real ao Brasil muda a arquitetura do Rio, disponível em: <http://www1.folha.uol.com.br/folha/brasil/ult96u372084.shtml> . Acessado em: 31 de maio de 2008 às $23 \mathrm{~h} 46 \mathrm{~min}$ 